\title{
The Impact of Interval Training on Cardiorespiratory Fitness, Body Composition, Physical Fitness, and Metabolic Parameters in Older Adults: a Systematic Review and Meta-Analysis
}

\author{
Zhi-Jian Wu \\ Nanjing normal university \\ Zhu-Ying Wang \\ Nanjing Normal University \\ Hao-En Gao \\ Nanjing Normal University \\ Xian-Feng Zhou \\ Nanjing Normal University
}

Fang Hui LI ( $\square$ 12356@njnu.edu.cn )

Nanjing Normal University https://orcid.org/0000-0003-2027-5151

Research article

Keywords: high-intensity interval training, older adults, cardiorespiratory fitness, meta-analysis

Posted Date: February 18th, 2020

DOI: https://doi.org/10.21203/rs.2.23869/v1

License: (c) (i) This work is licensed under a Creative Commons Attribution 4.0 International License.

Read Full License 


\section{Abstract}

Background: This review and meta-analysis aimed to evaluate the effects of high-intensity interval training (HIIT) on cardiorespiratory fitness, body composition, physical fitness, and health-related outcomes in older adults.

Methods: Four electronic databases (PubMed, Scopus, Medline, and Web of Science) were searched (until Oct 2019) for randomized trials comparing the effect of HIIT on physical fitness, metabolic parameters, and cardiorespiratory fitness in older adults. The Cochrane risk of bias assessment tool was used to evaluate the methodological quality of the included studies; Stata 14.0 software was used for statistical analysis.

Results: HIIT significantly improved the maximum rate of oxygen consumption (VO 2max) compared with a moderate-intensity continuous training (MICT) protocol (HIIT vs. MICT: weighted mean difference $=$ $2.04,95 \%$ confidence interval: $1.01-3.07, p<0.001)$. Additional subgroup analyses determined that training periods $>12 \mathrm{wks}$, training frequencies of 2 sessions/wk, session lengths of $40 \mathrm{~min}, 6$ sets and repetitions, training times per repetition of $>60 \mathrm{~s}$, and rest times of $<90 \mathrm{~s}$ are more effective for VO $2 \mathrm{max}$

Conclusions:This systematic review and meta-analysis showed that HIIT induces favorable adaptions in cardiorespiratory fitness, physical fitness, muscle power, cardiac contractile function, and citrate synthase activities in older individuals which may help to maintain aerobic fitness and slow down the process of sarcopenia.

\section{Background}

Human lifespans are rapidly increasing and the number of elderly $\geq 60$ years of age is expected to reach 2 billion by 2050 [1]. Increasing age is accompanied by diffuse alterations in cardiovascular structure and function resulting in an increased risk of cardiovascular disease (CVD), a major cause of mortality and morbidity [2]. The study by Dallas et al. [3], suggested that the pleiotropic effects of maintaining cardiorespiratory fitness (CRF) for the elderly have been more widely recognized, and epidemiological studies have shown that CRF (measured by the maximum rate of oxygen consumption: $\mathrm{VO}_{2 \max }$ ) is inversely associated with coronary heart disease, cardiovascular disease events, cancer, and all-cause mortality [4]. Moreover, a previous study suggested that age-related CRF loss is one factor that may contribute to sarcopenia and reduced exercise capacity in older adults by limiting the diffusion of oxygen [4]. This would exacerbate deleterious metabolic and oxidative stress in skeletal muscle and contribute to muscle fiber loss and muscular performance perturbations [5]. Therefore, CRF and muscular performances have been identified as two independent health indicators which have become a priority in promoting the health of older adults [6]. Strategies to prevent the age-related decline in CRF and muscular performance may help to prevent or slow the progression of sarcopenia and its associated functional declines in generally healthy older adults. 
Exercise training, in the form of resistance and aerobic training, can help adults maintain and improve aspects of $\mathrm{CRF}$ and muscle strength in older populations while concurrently reducing overall mortality [7]. Several prior meta-analyses confirmed the positive effects of resistance training on specific measures of upper and lower extremity muscle strength and muscle morphology in healthy older adults [8], but are controversial regarding CRF [9]. Even though the World Health Organization recommends concurrent endurance training ( $>150 \mathrm{~min} / \mathrm{wk}$ ) and resistance training ( $>2$ sessions/wk), a lack of free time is a major barrier to attaining these exercise goals [10]. In this regard, several small randomized trials utilizing less time-consuming high-intensity interval training (HIIT), characterized by brief intermittent bouts of high-intensity aerobic exercise, have emerged over recent years, and revealed impressive effects on cardiovascular health. HIIT have been shown to increase CRF and have had positive influences on muscle strength, oxidative stress, inflammation, and insulin sensitivity in healthy older adults $[1,2,4,11]$.

Although some studies have demonstrated that HIIT can improve metabolic health and $\mathrm{VO}_{2 \max }$ in the elderly, the results are controversial [12]. Most importantly, the characteristics of HIIT interventions most effective in improving CRF, muscle strength, and metabolic trait measures among older adults are not yet clear because no prior systematic reviews and meta-analyses have quantitatively explored moderators of HIIT effectiveness on these types of measures. Identifying the most effective HIIT interventions from development and testing to translation into practice for cardiorespiratory fitness, body composition, physical fitness, and health-related outcomes in the elderly is critical to efficiently advance this area of science.

The aim of this study was to systematically review the evidence and quantify the impact of HIIT on $\mathrm{VO}_{2 \max }$ compared with that of moderate-intensity continuous training (MICT), by evaluating various variables such as session length, intensity, frequency, repetitions, training time per repetitions, and rest times (rests between sets and repetitions). The dose-response relationship effectiveness of HIIT in terms of $\mathrm{VO}_{2 \mathrm{max}}$ in the elderly can then be used to modify the HIIT. Secondary aims included the investigation of the effects of HIIT on blood pressure, blood glucose, lipid profiles, muscle areas, citrate synthase (CS), ejection fractions (EF\%), and physical fitness: muscle power, timed up and go (TUG), 6 min Walking Test (6MWT), upper limb muscle strength (ULM), and lower limb muscle strength (LLM), for those who have undertaken such training. Promoting the health of the elderly using comprehensive and quantitative assessments regarding how HIIT affects their health status can provide recommendations for clinical practice and future research.

\section{Methods}

\subsection{Literature Search Strategy}

This study followed the preferred reporting items for systematic reviews and meta-analyses (PRISMA) guidelines. PubMed, Science Direct, Web of Science, and Sports Discus databases were searched using Boolean logic with the terms: "high-intensity interval training", "high-intensity intermittent exercise", "aerobic interval training", "vascular function", "cardiovascular function”, "cardiorespiratory fitness", 
"muscular strength", "VO ${ }_{2 m a x}$ ", "metabolism", "skeletal muscle" and "older". The search strategy was limited to older adults, and did not include animals, adolescents, or children. The publication dates of the articles were restricted to between the years when the databases were built and October 25, 2019.

\subsection{Type of interval training}

In the HIIT modality, short bursts of high-intensity exercise were alternated with periods of lower-intensity effort or complete rest for recovery [13]. In the last few years, HIIT has grown in popularity among athletes and as a strategy to counteract the adverse effects of metabolic disorders. This has led to a wide range of terms to describe HIIT protocols, such as aerobic interval training or high intensity intermittent exercises. Recently, the term HIIT should be used to design protocols with a target intensity 'near the maximal' effort (i.e., between 80 and $100 \%$ of the peak heart rate (HR)), while sprint interval training (SIT) is more appropriate for "all out" or "supramaximal" efforts $\left(\geq 100 \% \mathrm{VO}_{2 \max }\right)$. In addition, physiological and metabolic adaptations are different in SIT and HIIT [14]. For these reasons, we excluded studies from our analysis that involved SIT. When publications referred incorrectly to "SIT" or "Wingate" protocols (i.e., when subjects performed with an intensity level below $100 \%$ of the peak HR), the data was nevertheless included. In our meta-analysis, only running, cycling, and elliptical modalities were selected. There was no restriction regarding the duration of the protocol and the HIIT modality.

\subsection{Study Inclusion and Exclusion Criteria}

Inclusion criteria were selected by: (a) population; healthy subjects who were aged $\geq 60$ years, with a study mean age $\geq 65$ years. Participants were not restricted by body mass index (BMI), sex, pathologies, or ethnic origins, but high-level athletes were not included; (b) interventions; HIIT and MICT. HIIT was defined as activities with intermittent bouts of activity that were performed at maximal effort, $\geq 75 \%$ $\mathrm{VO}_{2 \max } \geq 75 \% \mathrm{HR}$ reserve, or a relative intensity of at least $85 \% \mathrm{HRmax}$. The study included a HIIT session lasting $\leq 4 \mathrm{~min} / \mathrm{set}$ interspersed with an interval of rest or active recovery; (c) randomized controlled trials or controlled clinical trials; $(d) \geq 4$ wks with interventions; and (e) outcome indicators; $\mathrm{VO}_{2 \max }(\mathrm{ml} / \mathrm{kg} / \mathrm{min}$ ) (the primary outcome), muscle power $(\mathrm{W})$, and body composition (i.e., BMl, body fat percentage (BF\%), and lean mass (LM)). Secondary outcomes were TUG, 6MWT, LLM, ULM, muscle area, SBP, DBP, HDL, LDL, glucose, HOMA-IR, triglycerides, EF\%, and skeletal muscle CS activities (with different units as seconds, $\mathrm{m}, \mathrm{N}, \mathrm{kg}, \mathrm{mmol} / \mathrm{L}, \mu \mathrm{mol} / \mathrm{g} / \mathrm{min}$ ). Exclusion criteria were as follows: (a) the article was written in Chinese; (b) one-time acute exercise studies; (c) interventions including HIIT training with diet or medicine; (d) HIIT without supervision.

\subsection{Data Collection or Data Synthesis}

The first author (Z.W.) extracted data from the studies with advice from F.L. on selection criteria. First, the title and abstract were screened, and then, if data were missing or interesting, the full text was analyzed. The data were then extracted if they met our criteria. Requests for missing data $\left(\mathrm{VO}_{2 m a x}\right.$, muscle power, TUG, 6MWT, ULM, LLM, BMI, BF\%, LM, muscle area, SBP, DBP, total cholesterol, HDL, LDL, glucose, HOMA$\mathrm{IR}$, triglycerides, EF\% and skeletal muscle CS activities, number of male/female subjects before and after 
the protocol, and age at the beginning of the study) were sent to corresponding authors when appropriate.

\subsection{Risk of bias assessment}

The Cochrane collaboration tool for assessing risk of bias (Revman 5.3, London, UK) was used to evaluate the quality of the included literature from primarily 6 domains: selection (sequence generation and allocation concealment), performance (blinding of participants/personnel), detection (blinding outcome assessors), attrition (incomplete outcome data), report (selective reporting), and other potential bias (e.g., recall bias) [15]. For each indicator, a "low risk of bias", "unclear risk of bias" and "high risk of bias" were used as judgments. The quality of the included literature was classified into three levels: level A (4 or more items of low risk were met), level B (2-3 items of low risk were met), and level C (1 or no items of low risk was met).

\subsection{Statistical Analysis}

$\mathrm{VO}_{2 \mathrm{max}}, \mathrm{TUG}, 6 \mathrm{MWT}, \mathrm{BMI}, \mathrm{BF} \%$, LM, muscle area, and EF\%, and given the consistency of variable units between the same outcome indicators among the continuous variables in the included studies, we compared the changes from baseline to end-point data among groups using weighted mean differences (WMD). Ninety-five \% confidence intervals (Cl) were used for pooled effect sizes [16]. While standardized mean differences (SMD) and 95\% Cls were used for each indicator unit inconsistency, outcomes included muscle power, ULM, LLM, SBP, DBP, total cholesterol, HDL, LDL, glucose, HOMA-IR, triglycerides, and skeletal muscle CS activities. According to the characteristics of the literature, HIIT training interval durations and energy expenditures were analyzed to test the effect of different subgroups. Statistical heterogeneity was examined using $\mathrm{I}^{2}$ and Cochran's Q-test among included studies. If the $\mathrm{p}$-value was < 0.1 , heterogeneity existed among studies; otherwise, homogeneity existed among the studies. Heterogeneity between studies was quantitatively evaluated by $\mathrm{I}^{2}$ (between 0 and $100 \%$, and $0 \%, 25 \%$, $50 \%$, and $75 \%$, indicating no heterogeneity, mild heterogeneity, moderate heterogeneity, and high heterogeneity, respectively) [17]. When heterogeneity was evident, a random-effects model was used to pool the data; otherwise, a fixed-effects model was used. An effect size greater than 0 with a $95 \% \mathrm{Cl}$ lower bound also greater than 0 would indicate an increase; otherwise, it would indicate a decrease. The Egger test was adopted to detect publication bias with bias indicated if $p<0.05$ [18]. Statistical analysis was performed using Stata1 2.0 (Meta-template) software.

HIIT must be applied appropriately by manipulating key programming variables (frequency, intensity, training interval, and recovery interval). Subcategories were created to extract the most important HIIT training variables from the following combinations: training volume (i.e., period, frequency, number of sets per exercise, number of repetitions per set); training intensity (i.e., intensity, time under tension); and rest (rest between sets and repetitions). For each subcategory, random-effects subgroup analysis was performed to identify variables that best predicted the improvement differences in measures of $\mathrm{VO}_{2 \mathrm{max}}$. Finally, the effects of HIIT and MICT on $\mathrm{VO}_{2 \mathrm{max}}$ in the elderly were compared. 


\section{Results}

\subsection{Study Selection}

The initial search retrieved 1,276 peer-reviewed articles from the various databases with 259 duplicates eliminated by using the literature manager, 769 irrelevant articles were eliminated by reading the titles and abstracts, and 23 relevant articles were traced by reading the relevant meta-analyses and systematic reviews. Ultimately, 241 potentially eligible articles remained and 26 controlled experiments $[1,2,19-42]$ were included after reading the full text (Fig. 1).

\subsubsection{Subject Characteristics}

Twenty-six articles were included in the study, with a total of 1,000 elderly participants; 5 of those studies $[2,20,24,39,41]$ contained 2 experiments, 3 studies $[20,24,41]$ compared gender differences in the health effects of HIIT in elderly people; and 5 studies [24, 25, 36-38] compared changes in maximal oxygen uptake by HIIT and MICT in older adults. The training frequency was $2-5$ times/wk, the training time was $20-40 \mathrm{~min} / \mathrm{session}$, and the cycle was 4-24 wks. The participants included in this study were trained using elliptical devices $[19,21,28]$, power bicycles, electronically braked cycle ergometers $[2,20$, $22,24,27,31,33-35,38,41]$, upper- and lower-body walking $[1,23,25,36]$, jogging, running $[29,30,32$, $37,39,40,42]$, and Xbox $360 \mathrm{~s}$ [26]. The following target intensities were used in the HIIT group: 80-85\% HRmax [19, 21, 28], 80-85\% VO2max [22], 80-90\% V02max [37], > 90\% HRmax [23], < 90\% HRmax [40], $\geq 70 \% \operatorname{VO} 2 \max [29,32], 70 \% 1$ repetition maximum (RM) [31], 90-95\% HRmax [25, 33, 34, 36, 38], > 90\% heart rate reserve (HRR) [35], 50\% of peak power output [2], 75- 93\% peak power output [39], and $124 \pm$ $3 \%$ of max power output with ratings of perceived exertion (RPE) from 11 to 13 [24, 26]. The following target intensities were used in the MICT group: 55-60\% HRmax [38], 70\% HRmax [25, 36], 51-65\% peak power output [39], and isoinertial resistance training [37]. VO2max was determined by stepwise increasing the load test combined with gas metabolic analyses. Seventeen studies contained cardiorespiratory fitness measures, 10 articles described the changes in the metabolic characteristics of elderly individuals during interval training, and 3 articles described the changes in muscle strength. Table 1 shows the basic characteristics of the included studies. 
Table 1

Characteristics of studies and subjects included in the review

\begin{tabular}{|c|c|c|c|c|c|c|}
\hline First author & $\begin{array}{l}\text { Published } \\
\text { years }\end{array}$ & $\begin{array}{l}\text { Sample } \\
\text { ratio (T/C) }\end{array}$ & $\begin{array}{l}\text { Age (years) } \\
(T / C)\end{array}$ & $\begin{array}{l}\text { Experimental } \\
\text { period }\end{array}$ & $\begin{array}{l}\text { Mode of } \\
\text { exercise }\end{array}$ & $\begin{array}{l}\text { Outcome } \\
\text { measures }\end{array}$ \\
\hline Fanny & 2019 & $14 / 14$ & $67.8 \pm 3.9$ & 12 weeks & HIIT & 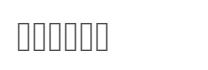 \\
\hline Ditte & 2019 & $22 / 14$ & $63 \pm 1$ & 6 weeks & HIIT & प्राप्रा \\
\hline Buckinx & 2019 & $15 / 15$ & $66.8 \pm 3.7$ & 12 weeks & HIIT & 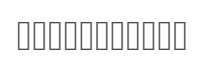 \\
\hline Buckinx & 2018 & $30 / 30$ & $68.1 \pm 4.2$ & 12 weeks & HIIT & 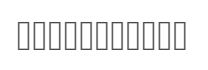 \\
\hline Losa & 2019 & $11 / 9$ & $84.0 \pm 4.7$ & 6 weeks & HIIT & 0 \\
\hline Morikawa & 2018 & $16 / 16$ & $65 \pm 4$ & 5 months & IWT & प्साप्रा \\
\hline Søgaard & 2017 & $11 / 11$ & $63 \pm 1$ & 6 months & HIIT & 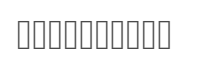 \\
\hline Søgaard & 2017 & $11 / 11$ & $63 \pm 1$ & 6 months & HIIT & 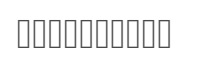 \\
\hline Moro & 2017 & $14 / 14$ & $64.1 \pm 2.3$ & 6 months & HIIRT & परापरा \\
\hline Masuki & 2017 & $12 / 12$ & $66 \pm 4$ & 5 months & IWT & Q \\
\hline Wyckelsma & 2017 & $8 / 7$ & $69.4 \pm 3.5$ & 12 weeks & HIIT & प \\
\hline Wyckelsma & 2017 & $8 / 8$ & $69.9 \pm 3.8$ & 12 weeks & HIIT & Q \\
\hline Sculthorpe & 2017 & $22 / 11$ & $\begin{array}{l}62.3 \pm \\
4.1 / 61.6 \pm \\
5.0\end{array}$ & 6 weeks & HIIT & Q \\
\hline Bruseghini & 2017 & $12 / 12$ & $68 \pm 4$ & 8 weeks & HIIT & 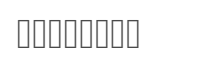 \\
\hline Ballin & 2019 & $36 / 36$ & 70 & 10 weeks & VIT & 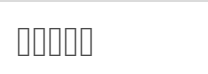 \\
\hline Grace & 2018 & $22 / 25$ & $62.7 \pm 5.2$ & 6 weeks & HIIT & Q \\
\hline Grace & 2018 & $17 / 19$ & $61.1 \pm 5.4$ & 6 weeks & HIIT & 0 \\
\hline
\end{tabular}

Data are expressed as means \pm standard deviations (SD). $\otimes V_{2} O_{2 \max }(\mathrm{ml} / \mathrm{kg} / \mathrm{min}) ; \otimes \mathrm{HOMA}-\mathrm{IR} ; \otimes \mathrm{TUG}(\mathrm{s}) ;$

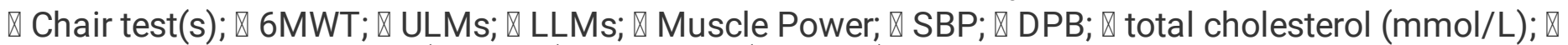

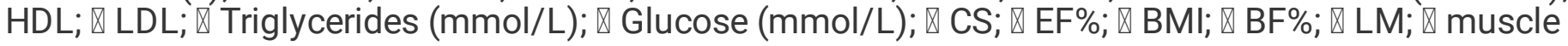
area $\left(\mathrm{cm}^{2}\right)$; Abbreviations: IWT: interval walking training, HIIRT: high-intensity interval resistance training, AIT: aerobic interval training, VIT: vigorous-exercise intensity group, IATP-R: interval aerobic training program with recovery bouts, $\mathrm{VO}_{2 \text { max }}$ : maximum oxygen consumption, $\mathrm{BMI}$ : body mass index, BF\%: body fat percentage, LM: lean mass, TUG: Timed Up and Go, 6MWT: 6-Minute Walking Test, LLM: lower limbs muscle strength, ULM: upper limbs muscle strength, SBP: systolic blood pressure, DPB: diastolic blood pressure, HDL: high density lipoprotein, LDL: low density lipoprotein, HOMA-IR: Homeostatic Model Assessment of Insulin Resistance, EF: ejection fractions, CS: skeletal muscle citrate synthase, HIIT: high-intensity interval training. 


\begin{tabular}{|c|c|c|c|c|c|c|}
\hline First author & $\begin{array}{l}\text { Published } \\
\text { years }\end{array}$ & $\begin{array}{l}\text { Sample } \\
\text { ratio (T/C) }\end{array}$ & $\begin{array}{l}\text { Age (years) } \\
(T / C)\end{array}$ & $\begin{array}{l}\text { Experimental } \\
\text { period }\end{array}$ & $\begin{array}{l}\text { Mode of } \\
\text { exercise }\end{array}$ & $\begin{array}{l}\text { Outcome } \\
\text { measures }\end{array}$ \\
\hline Hwang & 2016 & $15 / 14$ & $\begin{array}{l}64.8 \pm \\
1.4 / 63.8 \pm \\
1.6\end{array}$ & 8 weeks & HIIT & 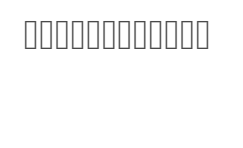 \\
\hline Molmen & 2012 & $16 / 16$ & $72 \pm 1$ & 12 weeks & AIT & प्राप्रा \\
\hline Ahmaidi & 1998 & $11 / 11$ & $63 \pm 5$ & 3 months & HIIT & प \\
\hline Lepretre & 2009 & $16 / 16$ & $\begin{array}{l}65.5 \pm \\
5.4 / 64.6 \pm \\
3.7\end{array}$ & 9 weeks & AIT & प्र \\
\hline Lepretre & 2009 & $19 / 19$ & $\begin{array}{l}65.5 \pm \\
5.4 / 65.3 \pm \\
4.5\end{array}$ & 9 weeks & AIT & प्रा \\
\hline Bell & 2017 & $11 / 14$ & $\begin{array}{l}65 \pm 1 / 63 \pm \\
2\end{array}$ & 8 weeks & HIIT & प्राप्रा \\
\hline Chrøis & 2019 & $11 / 11$ & $63 \pm 1$ & 6 weeks & HIIT & प्राप्रा \\
\hline Chrøis & 2019 & $11 / 11$ & $63 \pm 2$ & 6 weeks & HIIT & प्राप्रा \\
\hline Hwang & 2019 & $23 / 16$ & $\begin{array}{l}65 \pm 2 / 61 \pm \\
2\end{array}$ & 8 weeks & HIIT & 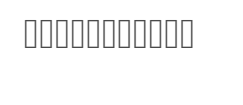 \\
\hline Santos & 2019 & $9 / 9$ & $69.1 \pm 5.0$ & 3 months & VIT & प्र \\
\hline Bouaziz & 2019 & $27 / 29$ & $\begin{array}{l}72.9 \pm \\
2.5 / 74.3 \pm \\
3.4\end{array}$ & 9.5 weeks & IATP-R & 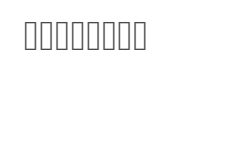 \\
\hline Currie & 2015 & $9 / 9$ & $63 \pm 8$ & 3 months & HIT & 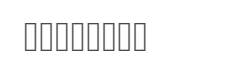 \\
\hline Currie & 2015 & $9 / 9$ & $63 \pm 8$ & 6 months & HIT & 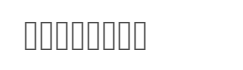 \\
\hline Hurst & 2019 & $18 / 18$ & $61.9 / 62.8$ & 12 weeks & HIT & प्रा \\
\hline \multicolumn{7}{|c|}{ 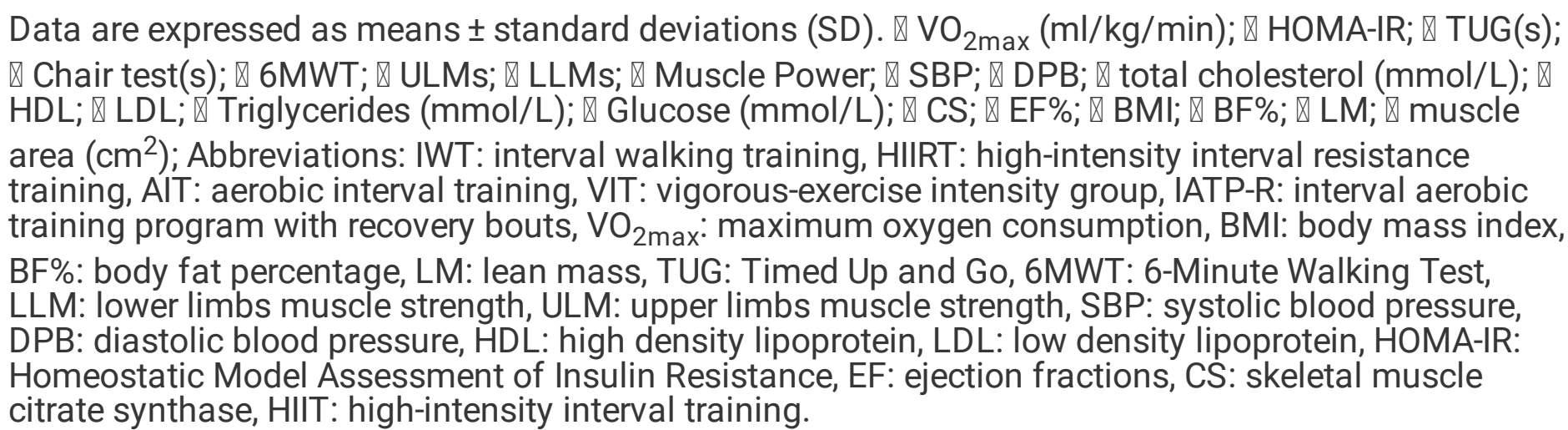 } \\
\hline
\end{tabular}

Figure 2 shows the method quality evaluation chart of the included studies. According to the literature quality evaluation criteria, 10 studies met 4 or more items of low risk and 16 studies met 2-3 items of 
low risk.

\subsection{Meta-analysis}

\subsubsection{Cardiorespiratory fitness}

All studies also evaluated $\mathrm{CRF}$ as $\mathrm{VO}_{2 \mathrm{max}}$, and a total of 16 studies with 21 experiments comparing changes in $\mathrm{VO}_{2 \max }$ which evaluated $\mathrm{CRF}$ using $\mathrm{VO}_{2 \max }$ in older adults after $\mathrm{HIIT}$ interventions illustrated moderate heterogeneity across the studies $\left(Q=81.26, d f=20, I^{2}=75.4 \%, p<0.001\right)$. As shown in Fig. $3 A$, $\mathrm{VO}_{2 \max }$ was significantly increased in the elderly after HIIT interventions (WMD $=2.16,95 \% \mathrm{Cl}$ : 1.47-2.84, $\mathrm{p}<0.001)$. Meanwhile, in 6 studies that included HIIT vs. MICT, $\mathrm{VO}_{2 \max }$ improved to a greater extent in HIITs (HIIT vs. MICT: WMD = 2.04, 95\% Cl: 1.01-3.07, p<0.001).

\subsubsection{Dose-Response Relationships of HIIT on Measures of $\mathrm{VO}_{2 \max }$}

Table 2 shows the results of the subgroup analysis on measures of $\mathrm{VO}_{2 \max }$ for 7 subcategories: training periods, session lengths, frequency, intensity, the number of sets and repetitions, the training time per repetition, and rest times between sets and repetitions. Table 3 shows the results of subgroup analysis for $\mathrm{VO}_{2 \max }$. In the training period subgroup, the training period of $<12 \mathrm{wks}\left(\mathrm{WMD}=1.59,95 \% \mathrm{Cl} 1 .-2.90 ; \mathrm{I}^{2}=\right.$ $77.2 \%, Q=48.26, d f=11, p<0.001)$ and the training period $\geq 12$ wks $\left(\mathrm{WMD}=2.94,95 \% \mathrm{Cl} 2.21-3.67 ; \mathrm{I}^{2}=\right.$ $63.9 \%, \mathrm{Q}=24.93, \mathrm{df}=9, \mathrm{p}<0.001)$ produced large $\mathrm{VO}_{2 \max }$ effects. In the training frequency subgroup, 2,3 , and 4 training sessions/wk produced large effects in the older adult $\mathrm{VO}_{2 \mathrm{max}}$, with mean WMDs of 3.00 (two sessions), 1.46 (three sessions), and 2.08 (three sessions). In the session training intervention time subgroup, each $20 \mathrm{~min}\left(\mathrm{WMD}=2.32,95 \% \mathrm{Cl} 1.79-2.85 ; \mathrm{I}^{2}=79.5 \%, \mathrm{Q}=39.04, \mathrm{df}=8, \mathrm{p}<0.001\right), 30 \mathrm{~min}$ $\left(\mathrm{WMD}=1.74,95 \% \mathrm{Cl} 1.27-2.21 ; \mathrm{I}^{2}=75.1 \%, \mathrm{Q}=28.51, \mathrm{df}=7, \mathrm{p}<0.001\right)$, and $40 \mathrm{~min}$ session $(\mathrm{WMD}=5.66$, $\left.95 \% \mathrm{Cl} 2.67-8.65 ; \mathrm{I}^{2}=0.00 \%, \mathrm{Q}=0.00, \mathrm{df}=1, \mathrm{p}<0.001\right)$ produced large $\mathrm{VO}_{2 \mathrm{max}}$ effects. In the training intensity subgroup, training intensity $\geq 80 \% \mathrm{VO}_{2 \max }$ and training intensity $<80 \% \mathrm{VO}_{2 \max }$ produced large effects in the older adult $\mathrm{VO}_{2 \text { max }}$, with mean WMDs of $1.83\left(\geq 80 \% \mathrm{VO}_{2 \max }\right)$ and $1.67\left(<80 \% \mathrm{VO}_{2 \max }\right)$. 
Table 2

Subcategory analysis of HIIT on $\mathrm{VO}_{2 \max }$

\begin{tabular}{|c|c|c|c|c|c|c|}
\hline Subcategories & No. of studies & $\mathbf{Q}$ & $\mathrm{I}^{2}(\%)$ & WMD & $95 \% \mathrm{Cl}$ & p \\
\hline \multicolumn{7}{|l|}{ Duration } \\
\hline$<12$ weeks & 12 & 48.26 & 77.2 & 1.59 & 1.29 to 2.90 & 0.000 \\
\hline$\geq 12$ weeks & 9 & 24.93 & 63.9 & 2.94 & 2.21 to 3.67 & 0.000 \\
\hline \multicolumn{7}{|l|}{ Frequency } \\
\hline 2 sessions/week & 6 & 29.1 & 79.4 & 3.00 & 2.03 to 3.96 & 0.000 \\
\hline 3 sessions/week & 11 & 13.85 & 27.8 & 1.46 & 1.09 to 1.82 & 0.000 \\
\hline 4 sessions/week & 3 & 27.83 & 92.8 & 2.08 & 1.57 to 2.58 & 0.000 \\
\hline \multicolumn{7}{|l|}{ Session length } \\
\hline $20 \mathrm{~min}$ & 9 & 39.04 & 79.5 & 2.32 & 1.79 to 2.85 & 0.000 \\
\hline $30 \mathrm{~min}$ & 8 & 28.51 & 75.1 & 1.74 & 1.27 to 2.21 & 0.000 \\
\hline $40 \mathrm{~min}$ & 2 & 0.07 & 0.00 & 5.66 & 2.67 to 8.65 & 0.000 \\
\hline \multicolumn{7}{|l|}{ Intensity } \\
\hline$\geq 80 \% \mathrm{VO}_{2 \max }$ & 14 & 47.08 & 72.4 & 1.83 & 1.51 to 2.15 & 0.000 \\
\hline$<80 \% \mathrm{VO}_{2 \max }$ & 7 & 36.99 & 82.1 & 1.67 & 1.07 to 2.27 & 0.000 \\
\hline \multicolumn{7}{|c|}{ Number of sets and repetitions } \\
\hline 4 & 7 & 36.48 & 80.8 & 2.24 & 0.49 to 3.99 & 0.012 \\
\hline 5 & 3 & 6.66 & 54.9 & 1.46 & 0.60 to 2.32 & 0.001 \\
\hline 6 & 1 & 0.04 & 0.00 & 2.63 & 0.73 to 4.53 & 0.007 \\
\hline 10 & 5 & 11.3 & 55.8 & 1.75 & 0.89 to 2.62 & 0.000 \\
\hline \multicolumn{7}{|c|}{ Time training per repetition } \\
\hline$\leq 60 \mathrm{~s}$ & 12 & 23.49 & 48.9 & 1.71 & 1.14 to 2.27 & 0.000 \\
\hline$>60 \mathrm{~s}$ & 7 & 45.18 & 84.5 & 2.50 & 0.82 to 4.17 & 0.004 \\
\hline \multicolumn{7}{|c|}{ Rest time (rest in between sets and repetitions) } \\
\hline$\leq 90 \mathrm{~s}$ & 9 & 35.25 & 74.5 & 2.25 & 1.43 to 3.07 & 0.000 \\
\hline
\end{tabular}

The data shown are means $\pm 95 \%$ confidence intervals $(\mathrm{Cl})$; the sizes of the plotted squares reflect the statistical weight of each study. WMD: weighted mean difference. 


\begin{tabular}{|lllllll|}
\hline Subcategories & No. of studies & $\mathbf{Q}$ & $\mathbf{I}^{2}(\%)$ & WMD & $\mathbf{9 5 \%} \mathbf{C l}$ & $\mathbf{P}$ \\
\hline$>90 \mathrm{~s}$ & 10 & 44.83 & 77.7 & 2.03 & 0.75 to 3.32 & 0.002 \\
\hline
\end{tabular}


Table 3

Combined results of physical fitness, EF\%, blood pressure, blood lipid and glucose

\begin{tabular}{|c|c|c|c|c|c|c|c|}
\hline & \multirow{2}{*}{$\begin{array}{l}\text { No. of } \\
\text { studies }\end{array}$} & \multicolumn{3}{|c|}{ heterogeneity test } & \multicolumn{3}{|c|}{ effect size } \\
\hline & & $\mathrm{Q}$ & $\begin{array}{l}\mathrm{I}^{2} \\
(\%)\end{array}$ & $\mathrm{P}$ & ES & $95 \% \mathrm{Cl}$ & ES P \\
\hline \multicolumn{8}{|l|}{ Physical fitness } \\
\hline TUG (s) & 4 & 5.93 & 49.4 & 0.110 & -0.58 & $\begin{array}{l}-1.11 \text { to } \\
-0.05\end{array}$ & 0.011 \\
\hline Chair test (s) & 4 & 1.22 & 0.0 & 0.750 & -3.86 & $\begin{array}{l}-5.11 \text { to } \\
-2.61\end{array}$ & 0.000 \\
\hline 6WMT (m) & 4 & 1.48 & 0.0 & 0.690 & 65.82 & $\begin{array}{l}37.65 \text { to } \\
94.0\end{array}$ & 0.000 \\
\hline ULM & 2 & 0.01 & 0.0 & 0.940 & 0.11 & $\begin{array}{l}-0.30 \text { to } \\
0.52\end{array}$ & 0.586 \\
\hline LLM & 3 & 1.79 & 0.0 & 0.410 & 0.18 & $\begin{array}{l}-0.18 \text { to } \\
0.55\end{array}$ & 0.324 \\
\hline Muscle power & 5 & 1.51 & 0.0 & 0.820 & 0.56 & 0.26 to 0.87 & 0.000 \\
\hline CS activities & 3 & 6.86 & 70.8 & 0.030 & 3.91 & 2.52 to 5.31 & 0.000 \\
\hline \multicolumn{8}{|l|}{ Body composition } \\
\hline $\mathrm{BF} \%$ & 12 & 3.72 & 0.0 & 0.980 & -0.97 & $\begin{array}{l}-1.52 \text { to } \\
-0.41\end{array}$ & 0.001 \\
\hline BMI & 13 & 67.99 & 82.3 & 0.000 & -0.12 & $\begin{array}{l}-0.84 \text { to } \\
-0.60\end{array}$ & 0.743 \\
\hline LM & 11 & 5.16 & 0.0 & 0.880 & 0.68 & 0.21 to 1.15 & 0.005 \\
\hline Muscle area & 4 & 0.75 & 0.0 & 0.860 & 0.40 & 0.22 to 0.58 & 0.000 \\
\hline Blood pressure SBP & 13 & 112.3 & 87.5 & 0.00 & -1.95 & $\begin{array}{l}-5.27 \text { to } \\
1.36\end{array}$ & 0.248 \\
\hline DBP & 13 & 87.97 & 84.1 & 0.00 & -0.38 & $\begin{array}{l}-0.86 \text { to } \\
0.10\end{array}$ & 0.125 \\
\hline $\mathrm{EF} \%$ & 4 & 21.55 & 86.1 & 0.00 & 1.32 & 0.31 to 2.33 & 0.010 \\
\hline
\end{tabular}

Note: The data shown are mean $\pm 95 \% \mathrm{Cl}$; the size of the plotted squares reflects the statistical weight of each study. Abbreviations: ES, effect size; TUG, Timed Up and Go; 6MWT, 6-Minute Walking Test; ULM, upper limbs muscle strength; LLM, lower limbs muscle strength; CS, citrate synthase; BF\%, body fat percentage; BMI, body mass index; LM, lean mass; SBP, systolic blood pressure; DBP, diastolic blood pressure; EF, ejection fraction; HDL, high density lipoprotein; LDL, low density lipoprotein. 


\begin{tabular}{|c|c|c|c|c|c|c|c|}
\hline Total cholesterol & 12 & 29.21 & 65.8 & 0.001 & -0.11 & $\begin{array}{l}-0.49 \text { to } \\
0.27\end{array}$ & 0.566 \\
\hline HDL & 13 & 28.07 & 57.3 & 0.005 & 0.30 & $\begin{array}{l}-0.01 \text { to } \\
0.61\end{array}$ & 0.059 \\
\hline LDL & 13 & 30.12 & 63.5 & 0.002 & -0.25 & $\begin{array}{l}-0.60 \text { to } \\
0.10\end{array}$ & 0.161 \\
\hline Triglycerides & 8 & 9.69 & 27.8 & 0.207 & -0.34 & $\begin{array}{l}-0.64 \text { to } \\
-0.03\end{array}$ & 0.032 \\
\hline HOMA-IR & 2 & 13.84 & 82.8 & 0.000 & -0.44 & $\begin{array}{l}-2.13 \text { to } \\
1.25\end{array}$ & 0.608 \\
\hline Glucose & 7 & 18.24 & 78.1 & 0.001 & -0.78 & $\begin{array}{l}-1.47 \text { to } \\
-0.10\end{array}$ & 0.025 \\
\hline \multicolumn{8}{|c|}{$\begin{array}{l}\text { Note: The data shown are mean } \pm 95 \% \text { Cl; the size of the plotted squares reflects the statistical weight } \\
\text { of each study. Abbreviations: ES, effect size; TUG, Timed Up and Go; } 6 \mathrm{MWT} \text {, 6-Minute Walking Test; } \\
\text { ULM, upper limbs muscle strength; LLM, lower limbs muscle strength; CS, citrate synthase; BF\%, body } \\
\text { fat percentage; BMI, body mass index; LM, lean mass; SBP, systolic blood pressure; DBP, diastolic } \\
\text { blood pressure; EF, ejection fraction; HDL, high density lipoprotein; LDL, low density lipoprotein. }\end{array}$} \\
\hline
\end{tabular}

In the number of sets and repetitions subgroup, the number of repetitions per set was $4,5,6$, and 10 . The mean WMDs for the number of sets and repetitions per exercise were $2.24\left(95 \% \mathrm{Cl} 0.49-3.99 ; \mathrm{I}^{2}=80.8 \%\right.$, $Q=36.48, d f=7, p<0.05), 1.46\left(95 \% \mathrm{Cl} 0.60-2.32 ; I^{2}=54.9 \%, Q=6.66, d f=3, p<0.05\right), 2.63(95 \% \mathrm{Cl}$ $\left.0.73-4.53 ; l^{2}=0.0 \%, Q=0.04, d f=1, p<0.05\right)$, and $1.75\left(95 \% \mathrm{Cl} 0.89-2.62 ; \mathrm{l}^{2}=55.8 \%, Q=11.3, d f=5, p\right.$ $<0.001)$, and were indicative of large effects. The time training per repetition $\leq 60 \mathrm{~s}$ subgroup (WMD $=$ $\left.1.71,95 \% \mathrm{Cl} 1.14-2.27 ; \mathrm{I}^{2}=48.9 \%, \mathrm{Q}=23.49, \mathrm{df}=12, \mathrm{p}<0.001\right)$ and the time training per repetition $>60 \mathrm{~s}$ subgroup $\left(\mathrm{WMD}=2.50,95 \% \mathrm{Cl} 0.82-4.17 ; \mathrm{I}^{2}=84.5 \%, \mathrm{Q}=45.18, \mathrm{df}=7, \mathrm{p}<0.05\right)$ produced large $\mathrm{VO}_{2 \max }$ effects. The rest time (rest between sets and repetitions) $\leq 90$ s subgroup (WMD $=2.25,95 \% \mathrm{Cl} 1.43-$ $\left.3.07 ; I^{2}=74.5 \%, Q=35.25, \mathrm{df}=9, \mathrm{p}<0.001\right)$ and the $>90$ s subgroup $\left(\mathrm{WMD}=2.03,95 \% \mathrm{Cl} 0.75-3.32 ; \mathrm{I}^{2}=\right.$ $77.7 \%, Q=44.83, \mathrm{df}=10, \mathrm{p}<0.05)$ showed large effects. The largest effects on measures of $\mathrm{VO}_{2 \max }$ were found for training periods of $\geq 12$ wks (WMD $=2.94)$, training frequencies of two sessions (WMD $=3.00)$, intervention times of $40 \mathrm{~min}$ for each session (WMD $=5.66)$, intensities of $\geq 80 \% \mathrm{VO}_{2 \max }(\mathrm{WMD}=1.83)$, a number of 6 sets and repetitions (WMD $=2.63)$, training times per repetition of $>60 \mathrm{~s}(\mathrm{WMD}=2.50)$ and rest times (rest between sets and repetitions) of $\leq 90 \mathrm{~s}(\mathrm{WMD}=2.25)$.

\subsubsection{Body composition}

Body composition parameters were measured using dual-energy X-ray absorptiometry (DXA) and anthropometric measures. A detailed overview of individual results across the included studies is provided in Table 3. Thirteen studies compared the changes of BMI in the elderly after HIIT with moderate heterogeneity among the studies. The meta-analysis for changes in BMI revealed a small effect for HIIT compared to those that were sedentary $\left(\mathrm{WMD}=-0.12,95 \% \mathrm{Cl}-0.84\right.$ to $-0.60 ; \mathrm{I}^{2}=82.3 \%, \mathrm{Q}=67.99, \mathrm{df}=12$, $p=0.743)$. 
A total of 12 experiments compared the changes of BF\% of the elderly after HIIT interventions with the meta-analysis revealing a large effect for HIIT compared to SED (WMD $=-0.97,95 \% \mathrm{Cl}-1.52$ to $-0.41 ; \mathrm{I}^{2}=$ $0.0 \%, Q=3.72, d f=11, p<0.001 ;$ Table 3 ). In addition, 7 studies compared the changes of LM and 4 compared the muscle area of the elderly after HIIT, with no heterogeneity among studies (Table 3 ). HIIT induced significant improvement in $L M\left(W M D=0.68,95 \% \mathrm{Cl} 0.21-1.15 ; \mathrm{I}^{2}=0.0 \%, Q=5.16, \mathrm{df}=10, p=\right.$ $0.005)$ and muscle area (WMD $\left.=0.40,95 \% \mathrm{Cl} 0.22-0.58 ; \mathrm{I}^{2}=0.0 \%, \mathrm{Q}=0.75, \mathrm{df}=3, \mathrm{p}<0.001\right)$ when compared to the non-active population group.

\subsubsection{Physical fitness}

A total of 4 studies compared TUG, chair test, and 6WMT changes in older adults after HIIT interventions (Table 3). The TUG (WMD = -0.58, 95\% Cl -1.11 to $-0.05 ; \mathrm{I}^{2}=49.4 \%, \mathrm{Q}=5.93, \mathrm{df}=3, \mathrm{p}=0.011$ ) and chair test $\left(\mathrm{WMD}=-3.86,95 \% \mathrm{Cl}-5.11\right.$ to $-2.61 ; \mathrm{I}^{2}=0.0 \%, \mathrm{Q}=1.22, \mathrm{df}=3, \mathrm{p}=0.000$ ) were significantly lower after HIIT interventions, but 6WMT was significantly higher (WMD =65.82, 95\% Cl 37.65-94.00; $\mathrm{I}^{2}=0.0 \%, \mathrm{Q}=$ $1.48, d f=3, p=0.001$ ) when compared with a non-active control population (Table 3 ). There were 2 studies that described changes in ULM and 3 studies that compared changes in LLM with good homogeneity across studies, and there was a tendency for HIIT to increase ULM (standardized mean difference $(S M D)=0.11,95 \% \mathrm{Cl}:-0.30$ to $\left.0.52 ; \mathrm{l}^{2}=0.0 \%, \mathrm{Q}=0.01, \mathrm{df}=1\right)$ and $\mathrm{LLM}(\mathrm{SMD}=0.18,95 \% \mathrm{Cl}$ : -0.18 to $\left.0.55 ; I^{2}=0.0 \%, Q=1.79, d f=2\right)$ in the elderly, but this finding was not statistically significant ( $p$ > 0.05 ; Table 3).

The change in muscle power of the elderly was measured by 4 leg extensor power rigs and 1 isokinetic dynamometer in 5 studies. The study also found that muscle strength was significantly higher in older adults after HIIT interventions (SMD $=0.56 ; 95 \% \mathrm{Cl}: 0.26-0.87 ; \mathrm{I}^{2}=0.0 \%, \mathrm{Q}=1.51, \mathrm{df}=4, \mathrm{p}<0.001$; Table 3). Moreover, the change in mitochondrial CS activities in skeletal muscles of the elderly was measured in 3 studies. CS activity is known to be a key activator of metabolic genes stimulating mitochondrial substrate utilization. The weighted mean SMD for the effects of HIIT on CS protein was 3.91 (95\% Cl: 2.52 to $5.31 ; I^{2}=70.8 \%, Q=6.86, d f=2, p<0.01$; Table 3 ), which was indicative of a large effect.

\subsubsection{Blood lipids and glucose}

7 studies also measured insulin sensitivity as assessed by fasting blood glucose and HOMA-IR (Table 3). Eight of the studies also measured triglycerides, and 13 of the studies also measured blood total cholesterol, HDLs, and LDLs (Table 3). The study also found that fasting blood glucose (SMD $=-0.78$, $95 \% \mathrm{Cl}:-1.47$ to $\left.-0.10 ; \mathrm{I}^{2}=78.1 \%, \mathrm{Q}=18.24, \mathrm{df}=6, \mathrm{p}=0.025\right)$, HOMA-IR (SMD = -0.44, 95\% Cl: -2.13 to 1.25 ; $\left.\mathrm{I}^{2}=92.8 \%, \mathrm{Q}=13.84, \mathrm{df}=1, \mathrm{p}=0.608\right)$, and triglycerides $\left(\mathrm{SMD}=-0.34,95 \% \mathrm{Cl}:-0.64\right.$ to $-0.03 ; \mathrm{I}^{2}=27.8 \%, \mathrm{Q}$ $=9.69, \mathrm{df}=7, \mathrm{p}=0.032$ ) were significantly lower in older adults after HIIT interventions. However, there was a tendency for HIIT to increase HDLs in the elderly (SMD $=0.30,95 \% \mathrm{Cl}:-0.01$ to $0.61 ; \mathrm{I}^{2}=57.3 \%, \mathrm{Q}=$ 28.07, $d f=12)(p=0.050)$.

\subsubsection{Blood pressure and EF\%}


A total of 4 experiments explored the changes of EF\% after HIIT interventions (Table 3). Studies in this review have shown an increased $\mathrm{EF} \%$ of $1.32\left(95 \% \mathrm{Cl}\right.$ : $\left.0.31-2.33 ; \mathrm{I}^{2}=86.1 \%, \mathrm{Q}=21.55, \mathrm{df}=3, \mathrm{p}=0.010\right)$ following HIIT. Additionally, BP was also evaluated by 13 studies in this review with variable findings. The method of BP measurements was relatively homogenous in 4 studies (SBP: $I^{2}=87.5 \%, Q=112.3, d f=12$; DBP: $\left.\mathrm{I}^{2}=84.1 \%, \mathrm{Q}=87.97, \mathrm{df}=12\right)$. The SBP (SMD $=-1.95,95 \% \mathrm{Cl}:-5.27$ to 1.36$)$ and DBP (SMD $=-0.38$, $95 \% \mathrm{Cl}:-0.86$ to 0.10 ) of the elderly after HIIT tended to decrease, but was not statistically significant ( $p>$ $0.05)$.

\subsection{Publication bias}

In this study, Egger's test used to assess publication bias was developed by Matthias Egger et al., in 1997 to overcome the shortcomings of the funnel method [18]. In practice, one determines the intercept and $95 \% \mathrm{Cl}$ of the linear regression equation and judges whether there is publication bias by whether its $95 \%$ $\mathrm{Cl}$ contains a 0 . If the intercept corresponds to $\mathrm{p}<0.05$ or the $95 \% \mathrm{Cl}$ does not include 0 , it indicates publication bias; otherwise, it indicates no publication bias. As shown in Table 4, the p-values for $\mathrm{VO}_{2 \max }$ TUG, chair test, 6WMT, ULM, LLM, muscle power, BF\%, BMI, LM, muscle area, SBP, DBP, total cholesterol, $\mathrm{HDL}$, LDL, triglycerides, glucose, and CS were all greater than 0.05 and the $95 \%$ Cls all contained 0 ; therefore, there was no publication bias in the included studies. The EF\% did indicate publication bias since the $\mathrm{p}$-value was $<0.05$ and the $95 \% \mathrm{Cl}$ did not include 0 . 
Table 4

Test for publication bias of each indicator

\begin{tabular}{|c|c|c|c|c|c|c|}
\hline Variable & $\beta$ & Standard error & $\mathrm{T}$ & $P>|t|$ & \multicolumn{2}{|c|}{ [95\% Conf. Interval] } \\
\hline $\mathrm{VO}_{2 \max }$ & 1.28 & 0.70 & 1.83 & 0.08 & -0.18 & 2.75 \\
\hline TUG & -5.89 & 1.73 & -3.41 & 0.08 & -13.33 & 1.54 \\
\hline Chair test & -0.24 & 1.30 & -0.19 & 0.87 & -5.86 & 5.37 \\
\hline $6 \mathrm{WMT}$ & 1.54 & 1.99 & 0.78 & 0.52 & -7.02 & 10.10 \\
\hline ULM & -- & -- & -- & -- & -- & -- \\
\hline LLM & 2.19 & 3.56 & 0.62 & 0.65 & -43.04 & 47.42 \\
\hline Muscle Power & 1.73 & 1.16 & 1.49 & 0.23 & -1.96 & 5.43 \\
\hline $\mathrm{BF} \%$ & -1.36 & 1.44 & -0.95 & 0.37 & -4.57 & 1.85 \\
\hline BMI & 0.00 & 1.17 & 0.00 & 1.00 & -2.58 & 2.58 \\
\hline LM & 1.13 & 1.40 & 0.81 & 0.44 & -2.03 & 4.30 \\
\hline Muscle area & 0.12 & 0.35 & 0.35 & 0.76 & -1.38 & 1.62 \\
\hline SBP & 1.18 & 3.15 & 0.37 & 0.72 & -5.75 & 8.10 \\
\hline DBP & -1.08 & 3.06 & -0.35 & 0.73 & -7.80 & 5.64 \\
\hline Total cholesterol & -1.85 & 2.15 & -0.86 & 0.41 & -6.72 & 3.02 \\
\hline $\mathrm{HDL}$ & 3.30 & 1.64 & 2.01 & 0.07 & -0.31 & 6.92 \\
\hline LDL & -2.87 & 1.94 & -1.48 & 0.17 & -7.19 & 1.44 \\
\hline Triglycerides & -0.14 & 1.84 & -0.08 & 0.94 & -4.50 & 4.21 \\
\hline Glucose & -8.06 & 4.16 & -1.94 & 0.15 & -21.29 & 5.17 \\
\hline CS & 3.54 & 9.70 & 0.37 & 0.78 & -119.66 & 126.75 \\
\hline $\mathrm{EF} \%$ & 10.45 & 0.28 & 36.82 & 0.00 & 9.23 & 11.67 \\
\hline \multicolumn{7}{|c|}{$\begin{array}{l}\text { Abbreviations: } \mathrm{VO}_{2 m a x} \text { maximal oxygen uptake; TUG, Timed Up and Go; } 6 \mathrm{MWT} \text {, 6-Minute Walking } \\
\text { Test; ULM, upper limbs muscle strength; LLM, lower limbs muscle strength; CS, citrate synthase; BF\%, } \\
\text { body fat percentage; BMI, body mass index; LM, lean mass; SBP, systolic blood pressure; DBP, } \\
\text { diastolic blood pressure; EF, ejection fraction; HDL, high density lipoprotein; LDL, low density } \\
\text { lipoprotein. }\end{array}$} \\
\hline
\end{tabular}

\section{Discussion}


As far as we are aware, this is the first systematic literature review and meta-analysis that provides an integrated overview of the general effectiveness of HIIT on measures of $\mathrm{VO}_{2 \max }(\mathrm{WMD}=2.16,95 \% \mathrm{Cl}$ : 1.47-2.84), with a significantly greater increase in $\mathrm{VO}_{2 \max }$ following HIIT compared with a MICT protocol (HIIT vs. MICT: $W M D=2.04,95 \% \mathrm{Cl}: 1.01-3.07, \mathrm{p}<0.001$ ). Additionally, training variables modifying the HIIT effects on measures of $\mathrm{VO}_{2 \text { max }}$, confirmed the outcomes that long term ( $\left.\geq 12 \mathrm{wks}\right)$ vs. short term periods ( $<12 \mathrm{wks}$ ), low ( $<2$ sessions/wk) vs. high frequencies ( $\geq 2$ sessions/wk), long ( $\geq$ $40 \mathrm{~min} / \mathrm{session}$ ) vs. short lengths ( $<40 \mathrm{~min} /$ session), 6 sets and repetitions, $>60$ s time training per repetition, and rest times between sets and repetitions of $\leq 90 \mathrm{~s}$, are more effective for $\mathrm{VO}_{2 \text { max }}$. Furthermore, the main finding of our analysis showed that HIIT significantly increased 6WMT and muscle power, and reduced TUG, chair test, skeletal muscle CS activities, and EF\% indicating that HIIT may be necessary to achieve beneficial cardiorespiratory and skeletal muscle mitochondrial adaptation in older individuals.

The function of HIIT has clinical utility in individuals in need of improved aerobic fitness because HIIT is able to rapidly increase $\mathrm{VO}_{2 \max }[1,2,4,11,43]$. The analysis of variables was based on data from 26 articles with a total of 1,000 elderly individuals. The present review showed that HIIT significantly improved $\mathrm{VO}_{2 \max }$ in the elderly, and $\mathrm{VO}_{2 \max }$ increased by $2.16 \mathrm{ml} / \mathrm{kg} / \mathrm{min}$ and $2.04 \mathrm{ml} / \mathrm{kg} / \mathrm{min}$ when compared with SED (WMD $=2.16)$ and MICT $(\mathrm{WMD}=2.04)$, respectively. This was supported by a metaanalysis conducted by Ramos et al., who found that $\mathrm{VO}_{2 \max }$ improved to a greater extent following 12 wks of HIIT (three times/wk) compared with MICT (14-46\% vs. 5-16\%, respectively) [11]. In agreement with this finding, previous studies performed on treadmills demonstrated that greater improvements in $\mathrm{VO}_{2 \max }$ in response to HIIT compared with MICT remained unchanged in non-active older adults. These positive findings are similar to past meta-analyses looking at HIIT intervention effects on patients with cardiometabolic disorders, cardiorespiratory fitness in children and adolescents, and patients with type 2 diabetes [44-46]. In addition, the previous meta-analysis studies showed that HIIT had a significant medium to large effect on $\mathrm{VO}_{2 \max }$ in normal-weight $(\mathrm{SMD}=0.83)$, overweight/obese $(\mathrm{SMD}=0.74)$, and recreational healthy young adults $(S M D=0.86)$ [47]. This implies that HIIT may be a more potent stimulus indirectly influencing $\mathrm{VO}_{2 \mathrm{max}}$ in older adults compared to young or overweight adults.

We also determined how training variables such as session length, intensity, frequency, repetitions, training time per repetition, and rest time (rest between sets and repetitions) modified the HIIT effects on measures of $\mathrm{VO}_{2 \max }$. The present review suggests that training at intensities $\geq 80 \mathrm{VO}_{2 \max }(\mathrm{SMD}=1.83)$ had larger effects compared with training at intensities $<80 \mathrm{VO}_{2 \max }(\mathrm{SMD}=1.67)$ in elderly adults. In agreement with this finding, HIIT protocols used for patients with vascular dysfunction with similar intensities may have a greater capacity to improve $\mathrm{VO}_{2 \max }$ in vascular dysfunction patients [13]. In addition, the present review also suggested that training for $\geq 12$ wks elicited larger beneficial effects enhancing $\mathrm{VO}_{2 \max }$ compared to HIIT training for $<12$ wks. This is consistent with a previous metaanalysis study in overweight/obese populations where HIIT performed for $<12$ wks appears to be less effective in improving $\mathrm{VO}_{2 \max }(S M D=0.74)$ than $\mathrm{HIIT}$ for $\geq 12$ wks $(S M D=1.20)$. Additionally, a training 
time per repetition of $>60 \mathrm{~s}$ is more effective for $\mathrm{VO}_{2 \max }$ [47]. The HIIT protocol used in this study consisted of longer terms and the training time per repetition compared with a previous meta-analysis study that included 53 studies, confirmed a training term of $\geq 4-12$ wks with a training time per repetition of $\geq 2 \mathrm{~min}$, which was recommended for healthy, overweight/obese, or athletic adults [48]. This implies that HIIT protocols used to achieve beneficial cardiorespiratory fitness adaptations in older individuals should consist of longer terms with shorter training times per repetition.

Additionally, 6 sets and repetitions with rest times between sets and repetitions $\leq 90 \mathrm{~s}$ were more effective for $\mathrm{VO}_{2 \text { max }}$. In the training frequency subgroup, 2 training sessions/wk (WMD =3.00) produced large $\mathrm{VO}_{2 \max }$ effects related to $3(\mathrm{WMD}=1.46)$ and 4 training sessions/wk. In disagreement with this finding, HIIT protocols used for vascular dysfunction patients included 3 training sessions/wk, 4 sets and repetitions, and $3 \mathrm{~min}$ of active recovery had a greater capacity to improve $\mathrm{VO}_{2 \max }$ [13]. The HIIT protocol used in this study recommended inclusion of supervised sessions (i.e., $6 \times>60 \mathrm{~s} \mathrm{HIIT}$ at $\times 80 \% \mathrm{VO}_{2 \text { max }} \leq$ 90 s recovery, 2 times/wk for over 12 wks) to effectively improve $\mathrm{VO}_{2 \text { max }}$. Indeed, in the training session length subgroup, a session length of $\geq 40 \mathrm{~min} /$ session was more effective for $\mathrm{VO}_{2 \max }$. While the American College of Sports Medicine states [49] that older adults should accumulate 150-300 min/wk (30-60 min/ $\mathrm{d} \times 5$ times/wk) of moderate intensity aerobic exercise, accumulating only $80 \mathrm{~min} / \mathrm{wk}$ (40 min/ $\mathrm{d} \times 2$ times/wk) indicated that HIIT may be more effective in improving CRF in older adults when compared to MICT protocols [50].

WMT is the most commonly applied measure of endurance walking capacity and is valid for estimating $\mathrm{VO}_{2 \mathrm{max}}$ in the elderly. Improvements in the 6WMT are valuable goals for the elderly in whom functional capacity is severely compromised [51]. Our meta-analysis data also revealed that HIIT has the potential to increase 6WMT by $65.82 \mathrm{~m}$, which is consistent with previous data that demonstrated that HIIT can upregulate the 6WMT by $68 \mathrm{~m}$ in the elderly [28]. Moreover, endurance walking capacity is positively associated with mitochondrial function since $\mathrm{CS}$ is a core enzyme of the tricarboxylic acid cycle and directly controls mitochondrial oxidative capacity. A previous study showed that 12 wks of HIIT increased skeletal muscle CS activity (55\%) and mitochondrial content in older adults [34]. Our previous animal study indicated that HIIT can up-regulate mitochondrial CS content in the skeletal muscle of aged rats which is consistent with the current meta-analysis results showing a marked increase in CS activity in skeletal muscles of the elderly with HIIT interventions [52]. This coincided with improved endurance walking capacity and increased utilization of glucose and lipids, suggesting that the HIIT-induced increase in CS activity and subsequent increase in mitochondrial ATP biosynthesis may exert protective effects against the loss of age-associated endurance performance in older adults.

Central adaptations may be partly responsible for the greater improvements in CRF in response to HIIT [36]. Cardiac contractile function, as assessed by $\mathrm{EF} \%$, was associated with a greater improvement in aerobic fitness. A recent study reported a $4-8 \%$ increase in $\mathrm{EF} \%$ in older adults after 8-12 wks of HIIT training on a treadmill, but not so with MICT [36]. In agreement with previous randomized studies, our study found a marked increase (1.32\%) in EF\% in elderly individuals derived from a total of 4 meta- 
analysis experiments after HIIT. Studies in older adults have shown that HIIT can also be effective in inducing left ventricular remodeling, but resulted in no improvements in cardiac diastolic function and greater improvements in systolic function [53]. This is consistent with data from our meta-analysis which demonstrated that HIIT did not show significant results with regard to the SBP and DBP of the elderly, although SBP and DBP are usually consistent in aging and we did exclude individuals with cardiovascular disease [54]. Finally, the current meta-analysis provided evidence that HIIT also improved cardiac function in older adults who are free of cardiovascular and other major clinical diseases.

Recent research suggesting a reduction in TUG time by $0.8-1.4 \mathrm{~s}$ demonstrates a clinically significant improvement in physical function [55]. Small differences in TUG time may also improve fall risks [56]. TUG, induced by HIIT, was reduced by $0.58 \mathrm{~s}$ and was accompanied by a reduction of $3.86 \mathrm{~s}$ in the chair test with similar improvements previously reported in studies using resistance training [57]. This study found that HIIT could increase the muscle power of the elderly by 0.56 standard deviations (SD), and the strength of the upper and lower limbs also tended to increase. Indeed, the growth of even small muscle forces can have a large impact on fitness functional capacity and flexibility. Previous studies also found that after $12 \mathrm{wks}$ of intermittent resistance training, the output power of the elderly increased from 96 to $116 \%$, which is consistent with the results of the present study. This finding has clear practical implications as improvements in leg strength have been shown to make an important contribution to clinically meaningful improvements in chair test times and are related to improvements in functional performance. These results suggest that clinicians should consider whether there is a need for older participants to undertake HIIT if the primary goal is to improve strength and potentially reduce the risk of falls and fractures in older adults.

Age-related changes in body composition are associated with declining physical endurance, power, and slower gaits in older adults, while HIIT leads to decreased adiposity and increased muscle mass, as well as improved clinical outcomes in a number of age-related metabolic disorders, including visceral fat and insulin sensitivity $[38,57]$. Our meta-analysis showed that a total of 12 meta-analysis experiments had a larger effect in reducing BF\% than the changes of LM and muscle area of the elderly from 11 and 4 studies after HIIT, respectively. These results seem to suggest that HIIT had a greater potential to improve the $\mathrm{BF} \%(\mathrm{WMD}=-0.97)$ in healthy older adults compared with the potential to increase muscle area $(W M D=0.40)$ and $L M(W M D=0.68)$. These findings are in line with the results of Bruseghini et al., (2015), who examined the effects of HIIT on BF\%, LM, and muscle area in healthy older adults and reported decreases in BF\% larger than increases in muscle area size and LM [37]. Indeed, it has been suggested that a greater tendency for HIIT to decrease the accumulation of abdominal fat and induce a lipolysis metabolism is consistent with HIIT interventions found to significantly reduce triglycerides (SMD $=-0.34$ ) in older adults. Although previous studies have shown a positive effect of HIIT interventions on total cholesterol, HDL, and LDL in older adults with central obesity, this was not found in the present study possibly due to a lack of lipid metabolic disorders $[1,53,58]$.

In the current study, 2 of the studies also measured insulin sensitivity as assessed by blood glucose and 7 measured HOMA-IR following HIIT in healthy elderly adults. No changes were noted except a decreasing 
trend in HOMA-IR (SMD = -0.44) which may have been due to the lack of power in studies due to small sample sizes. Our findings disagree with results previously reported which indicated that HOMA-IR was reduced significantly following 8-wk all-extremity HIIT which included decreases in insulin sensitivity [36]. Additionally, our findings confirm those of previous investigations that a decrease of glucose (SMD = -0.78) induced by HIIT was accompanied by a gain in LM and skeletal muscle CS activities suggesting that the increase of total muscle mass and mitochondrial oxidative phosphorylation may be help remove glucose even in a group of elderly individuals [37].

The effects of HIIT on measures of muscle power and health-related outcomes have to be considered as preliminary because based on our selected inclusion criteria our systematic search identified only 2 studies dealing with ULMs and HOMA-IRs and only 3 dealing with LLMs and CSs. Secondly, information regarding individuals' characteristics were often incomplete (e.g., gender, age) and results were inconclusively reported (e.g., means and standard deviations) so that in several cases we were not able to compute the SMD. In addition, large heterogeneity was found across studies, which implies a large variability in the tested muscle strength variables (i.e., tests for ULM and LLM). Furthermore, except for modifying the training variables used to measure the effects of $\mathrm{VO}_{2 \mathrm{max}}$, it is a major limitation that such analyses fail to provide insights into how HIIT variables modify the characteristics of physical fitness, muscle size, or health-related outcomes in older adults due to inconclusively reported results.

Despite these limitations, this systematic review and meta-analysis was the first to provide an adequate overview of HIIT effects on measures of body composition, physical fitness, muscle size, health-related outcomes, and HIIT variables on $\mathrm{VO}_{2 \max }$. The present meta-analysis analyzed older adults who commenced HIIT to mitigate the age-related losses of muscle strength and mass, endurance capacity, $\mathrm{EF} \%$, and $\mathrm{CS}$ activities. Furthermore, to investigate the effects of training variables on $\mathrm{VO}_{2 \max }$ for slowing age-related CRF loss, a possible combination of HIIT subcategories was created on the basis of the best applicability for practitioners and clinicians.

\section{Conclusions}

Our meta-analysis provided evidence that HIIT may be a more potent stimulus influencing $\mathrm{VO}_{2 \text { max }}$ relative to MICT in older adults. HIIT results recommend the inclusion of supervised sessions (i.e., $6 \times>60$ s HIIT at $x>80 \% \mathrm{VO}_{2 \max } \leq 90$ s recovery, 2 times/wk for $>12 \mathrm{wks}$ ) and elicited clear beneficial effects for enhancing $\mathrm{VO}_{2 \max }$ compared to a non-active control population. Furthermore, HIIT is a feasible and effective method to improve body composition, physical fitness, and glucolipid metabolic disorders in older adults. These findings need to be confirmed with additional large, well-designed, randomized controlled trials. Comprehensive research designs, utilizing a combination of HIIT variables such as duration intervals, duration of recovery periods, sets and repetitions, intensities and frequencies for exercise interventions are recommended for prospective future research in this area of science.

\section{Abbreviations}


HIIT High-intensity interval training

MICT Moderate-intensity continuous training

PRISMA Preferred reporting items for systematic reviews and meta-analysis

WHO World health organization

CVD Cardiovascular disease

CRF Cardiorespiratory fitness

CS Citrate synthase,

EF\% Ejection fractions,

TUG Timed up and go,

6MWT 6 min Walking Test,

ULM Upper limb muscle strength

LLM Lower limb muscle strength

SIT Sprint interval training

BMI Body mass index

BF\% Body fat percentage

LM Lean mass

WMD Weighted mean differences

Cl Confidence intervals

SMD Standardized mean differences

ES Effect size

SBP Systolic blood pressure

DBP Diastolic blood pressure

HDL High density lipoprotein

LDL Low density lipoprotein. 
$\mathrm{VO}_{2 \max }$ Maximal oxygen uptake

HRR Heart rate reserve

RM Repetition maximum

\section{Declarations}

\section{Acknowledgements}

We would like to thank those who supported the project, including the Nanjing Municipal Bureau of Sports of the coordination committee.

\section{Ethics approval and consent to participate}

Not declared.

\section{Consent for publication}

Not declared.

\section{Availability of data and material}

Not applicable.

\section{Authors' contributions}

WZ and LF contributed to the conception and design of the study. WZ and ZX searched the databases. WZ and GH performed the statistical analysis and wrote the first draft of the manuscript. WZ and LF modified sections of the manuscript. All authors contributed to manuscript revision, read, and approved the submitted version.

\section{Funding}

This work was supported by the National Natural Science Foundation of China [Grant No. 31500961, 31971099] and the Natural Science Fund for Colleges and Universities of Jiangsu Province [Grant No. 18KJB180011].

\section{Conflicts of Interest}

There are no conflicts of interest to declare.

\section{References}


1. Ballin $M$, Lundberg E, Sorlen N, Nordstrom P, Hult A, Nordstrom A. Effects of interval training on quality of life and cardiometabolic risk markers in older adults: a randomized controlled trial. Clin Interv Aging. 2019; 14:1589-1599.

2. Grace F, Herbert P, Elliott AD, Richards J, Beaumont A, Sculthorpe NF. High intensity interval training (HIIT) improves resting blood pressure, metabolic (MET) capacity and heart rate reserve without compromising cardiac function in sedentary aging men. Exp Gerontol. 2018;109:75-81.

3. Dallas KB, Rogo-Gupta L, Elliott CS. What Impacts the All Cause Risk of Reoperation after Pelvic Organ Prolapse Repair? A Comparison of Mesh and Native Tissue Approaches in 110,329 Women. J Urol. 2018: 200:389-396.

4. Knowles AM, Herbert P, Easton C, Sculthorpe N, Grace FM. Impact of low-volume, high-intensity interval training on maximal aerobic capacity, health-related quality of life and motivation to exercise in ageing men. Age (Dordr). 2015;37:25.

5. Kaminsky LA, Arena R, Beckie M, Brubaker PH, Church TS, Forman DE, et al. The importance of cardiorespiratory fitness in the United States: the need for a national registry: a policy statement from the American Heart Association. Circulation. 2013; 127:652-662.

6. Lee DC, Artero EG, Sui X, Blair SN. Mortality trends in the general population: the importance of cardiorespiratory fitness. J Psychopharmacol.2010;24:27-35.

7. Amaro-Gahete FJ, De-la-OA, Jurado-Fasoli L, Dote-Montero M, Gutiérrez Á, Ruiz JR, et al. Changes in Physical Fitness After 12 Weeks of Structured Concurrent Exercise Training, High Intensity Interval Training, or Whole-Body Electromyostimulation Training in Sedentary Middle-Aged Adults: A Randomized Controlled Trial. Front Physiol. 2019;10:451.

8. Lacroix A, Gu F, Gallardo W, Pivonello R, Yu Y, Witek P, Boscaro M, et al. Efficacy and safety of oncemonthly pasireotide in Cushing's disease: a 12 month clinical trial. Lancet Diabetes Endocrinol. 2018;6:17-26.

9. Robinson MM, Dasari S, Konopka AR, Johnson ML, Manjunatha S, Esponda RR, et al. Enhanced Protein Translation Underlies Improved Metabolic and Physical Adaptations to Different Exercise Training Modes in Young and Old Humans. Cell Metab. 2017;25: 581-592.

10. Gomez-Lopez M, Gallegos AG, Extremera AB. Perceived barriers by university students in the practice of physical activities. J Sports Sci Med. 2010;9: 374-381.

11. Ramos JS, Dalleck LC, Tjonna AE, Beetham KS, Coombes JS. The impact of high-intensity interval training versus moderate-intensity continuous training on vascular function: a systematic review and meta-analysis. Sports Med. 2015;45: 679-692.

12. Taylor KL, Weston $M$, Batterham AM. Evaluating intervention fidelity: an example from a highintensity interval training study. PLOS ONE 2015;10:e125166.

13. Jelleyman C, Yates T, O'Donovan G, Gray LJ, King JA, Khunti K, et al. The effects of high-intensity interval training on glucose regulation and insulin resistance: a meta-analysis. Obes Rev. 2015;16:942-961. 
14. Karlsen T, Aamot IL, Haykowsky M, Rognmo O. High Intensity Interval Training for Maximizing Health Outcomes. Prog Cardiovasc Dis. 2017;60:67-77.

15. Moher D, Liberati A, Tetzlaff J, Altman DG. Preferred reporting items for systematic reviews and meta-analyses: the PRISMA statement. J Clin Epidemiol. 2009;62:1006-1012.

16. Costigan SA, Eather N, Plotnikoff RC, Taaffe DR, Lubans DR. High-intensity interval training for improving health-related fitness in adolescents: a systematic review and meta-analysis. $\mathrm{Br} \mathrm{J}$ Sports Med. 2015; 49:1253-1261.

17. Keating SE, Johnson NA, Mielke GI, Coombes JS. A systematic review and meta-analysis of interval training versus moderate-intensity continuous training on body adiposity. Obes Rev. 2017;18:943964.

18. Duval S,Tweedie R. Trim and Fill: A Simple Funnel-Plot-Based Method of Testing and Adjusting for Publication Bias in Meta-Analysis. Biometrics.2000;56:455-463.

19. Buckinx F, Marcangeli V, Pinheiro Carvalho L, Dulac M, Hajj Boutros G, et al. Initial Dietary Protein Intake Influence Muscle Function Adaptations in Older Men and Women Following High-Intensity Interval Training Combined with Citrulline. Nutrients. 2019; 11:1685.

20. Søgaard D, Baranowski M, Larsen S, Taulo Lund M, Munk Scheuer C, Vestergaard Abildskov C et al. Muscle-Saturated Bioactive Lipids Are Increased with Aging and Influenced by High-Intensity Interval Training. Int J Mol Sci. 2019; 20: 1240.

21. Buckinx F, Gaudreau P, Marcangeli V, Boutros GEH, Dulac MC, Morais JA, et al. Muscle adaptation in response to a high-intensity interval training in obese older adults: effect of daily protein intake distribution. Aging Clin Exp Res. 2019;31:863-874.

22. Losa-Reyna J, Baltasar-Fernandez I, Alcazar J, Navarro-Cruz R, Garcia-Garcia FJ, Alegre LM, et al. Effect of a short multicomponent exercise intervention focused on muscle power in frail and pre frail elderly: A pilot trial. Exp Gerontol. 2019;115: 114-121.

23. Hurst $\mathrm{C}$, Weston $\mathrm{KL}$, Weston $\mathrm{M}$. The effect of 12 weeks of combined upper- and lower-body highintensity interval training on muscular and cardiorespiratory fitness in older adults. Aging Clin Exp Res. 2019; 31: 661-671.

24. Chrøis KM, Dohlmann TL, Søgaard D, Hansen CV, Dela F, Helge JW, et al. Mitochondrial adaptations to high intensity interval training in older females and males. Eur J Sport Sci. 2020; 20: 135-145.

25. Hwang CL,Lim J,Yoo JK, Kim HK, Hwang MH, Handberg EM, et al. Effect of all-extremity highintensity interval training vs. moderate-intensity continuous training on aerobic fitness in middleaged and older adults with type 2 diabetes: A randomized controlled trial. Exp Gerontol. 2019;116:46-53.

26. Santos G, Wolf R, Silva MM, Rodacki A, Pereira G. Does exercise intensity increment in exergame promote changes in strength, functional capacity and perceptual parameters in pre-frail older women? A randomized controlled trial. Exp Gerontol. 2019;116:25-30.

27. Bouaziz W, Lang PO, Schmitt E, Leprêtre PM, Lefebvre F, Momas C, et al. Effects of a short-term interval aerobic training program with recovery bouts on vascular function in sedentary aged 70 or 
over: A randomized controlled trial. Arch Gerontol Geriatr. 2019; 82:217-225.

28. Buckinx F, Gouspillou G, Carvalho LP, Marcangeli V, El Hajj Boutros G, Dulac M, et al. Effect of HighIntensity Interval Training Combined with L-Citrulline Supplementation on Functional Capacities and Muscle Function in Dynapenic-Obese Older Adults. J Clin Med. 2018;7:561.

29. Morikawa M, Nakano S, Mitsui N, Murasawa H, Masuki S, Nose H. Effects of dried tofu supplementation during interval walking training on the methylation of the NFKB2 gene in the whole blood of older women. J Physiol Sci.2018; 68:749-757.

30. Sogaard D, Lund MT, Scheuer CM. High-intensity interval training improves insulin sensitivity in older individuals. Acta Physiol (Oxf). 2018; 222:e13009.

31. Moro T, Tinsley G, Bianco A, Gottardi A, Gottardi GB, Faggian D, et al. High intensity interval resistance training (HIIRT) in older adults: Effects on body composition, strength, anabolic hormones and blood lipids. Exp Gerontol. 2017;98:91-98.

32. Masuki S, Nishida K, Hashimoto S, Morikawa M, Takasugi S, Nagata M, Taniguchi S et al. Effects of milk product intake on thigh muscle strength and NFKB gene methylation during home-based interval walking training in older women: A randomized, controlled pilot study. PLoS ONE 2017; 12 : e0176757.

33. Wyckelsma VL, Levinger I, Murphy RM, Petersen AC, Perry BD, Hedges CP, et al. Intense interval training in healthy older adults increases skeletal muscle [3H] ouabain-binding site content and elevates $\mathrm{Na+,K+-ATPase} \mathrm{a2} \mathrm{isoform} \mathrm{abundance} \mathrm{in} \mathrm{Type} \mathrm{II} \mathrm{fibers.} \mathrm{Physiol} \mathrm{Rep.} \mathrm{2017;} \mathrm{5:e13219.}$

34. Wyckelsma VL, Levinger I, McKenna MJ, Formosa LE, Ryan MT, Petersen AC, et al. Preservation of skeletal muscle mitochondrial content in older adults: relationship between mitochondria, fibre type and high-intensity exercise training. J Physiol (Lond.). 2017;595: 3345-3359.

35. Sculthorpe NF, Herbert P, Grace F. One session of high-intensity interval training (HIIT) every 5 days, improves muscle power but not static balance in lifelong sedentary ageing men: A randomized controlled trial. Medicine (Baltimore). 2017;96:e6040.

36. Hwang CL, Yoo JK, Kim HK, Hwang MH, Handberg EM, Petersen JW, et al. Novel all-extremity highintensity interval training improves aerobic fitness, cardiac function and insulin resistance in healthy older adults. Exp Gerontol. 2016;82:112-119.

37. Bruseghini P, Calabria E, Tam E, Milanese C, Oliboni E, Pezzato A, et al. Effects of eight weeks of aerobic interval training and of isoinertial resistance training on risk factors of cardiometabolic diseases and exercise capacity in healthy elderly subjects. Oncotarget. 2015;6:16998-17015.

38. Bell KE, Seguin C, Parise G, Baker SK, Phillips SM. Day-to-Day Changes in Muscle Protein Synthesis in Recovery From Resistance, Aerobic, and High-Intensity Interval Exercise in Older Men. J Gerontol A Biol Sci Med Sci. 2015;70:1024-1029.

39. Currie KD, Bailey KJ, Jung ME, McKelvie RS, MacDonald MJ. Effects of resistance training combined with moderate-intensity endurance or low-volume high-intensity interval exercise on cardiovascular risk factors in patients with coronary artery disease. J Sci Med Sport. 2015;18:637-642. 
40. Molmen HE, Wisloff U, Aamot IL, Stoylen A, Ingul CB. Aerobic interval training compensates age related decline in cardiac function. Scand Cardiovasc J. 2012; 46:163-171.

41. Lepretre PM, Vogel T, Brechat PH, Dufour S, Richard R, Kaltenbach G,et al. Impact of short-term aerobic interval training on maximal exercise in sedentary aged subjects. Int J Clin Pract. 2009; 63:1472-1478.

42. Ahmaidi S, Masse-Biron J, Adam B, Choquet D, Freville M, Libert JP, Prefaut C. Effects of interval training at the ventilatory threshold on clinical and cardiorespiratory responses in elderly humans. Eur J Appl Physiol Occup Physiol. 1998;78:170-176.

43. Su L, Fu J, Sun S, Zhao G, Cheng W, Dou C, Quan M. Effects of HIIT and MICT on cardiovascular risk factors in adults with overweight and/or obesity: A meta-analysis. PLoS ONE.2019;14:e0210644.

44. Weston KS, Wisloff U, Coombes JS. High-intensity interval training in patients with lifestyle-induced cardiometabolic disease: a systematic review and meta-analysis. Br J Sports Med. 2014; 48: 12271234.

45. Campbell WW, Kraus WE, Powell KE, Haskell WL, Janz KF, Jakicic JM, et al. High-Intensity Interval Training for Cardiometabolic Disease Prevention. Med Sci Sports Exerc. 2019;51:1220-1226.

46. Lora-Pozo I, Lucena-Anton D, Salazar A, Galán-Mercant A, Moral-Munoz JA. Anthropometric, Cardiopulmonary and Metabolic Benefits of the High-Intensity Interval Training Versus Moderate, Low-Intensity or Control for Type 2 Diabetes: Systematic Review and Meta-Analysis. Int J Environ Res Public Health. 2019; 16:4524.

47. Batacan RJ, Duncan MJ, Dalbo VJ, Tucker PS, Fenning AS. Effects of high-intensity interval training on cardiometabolic health: a systematic review and meta-analysis of intervention studies. $\mathrm{Br} \mathrm{J}$ Sports Med. 2017;51:494-503.

48. Wen D, Utesch T, Wu J, Robertson S, Liu J, Hu G, Chen H. Effects of different protocols of high intensity interval training for V02max improvements in adults: A meta-analysis of randomised controlled trials. J Sci Med Sport. 2019; 22:941-947.

49. American College of Sports Medicine, Chodzko-Zajko WJ, Proctor DN, Fiatarone Singh MA, Minson CT, Nigg CR, et al. American College of Sports Medicine position stand. Exercise and physical activity for older adults. Med Sci Sports Exerc. 2009; 41:1510-1530.

50. Cao M, Quan M, Zhuang J. Effect of High-Intensity Interval Training versus Moderate-Intensity Continuous Training on Cardiorespiratory Fitness in Children and Adolescents: A Meta-Analysis. Int J Environ Res Public Health 2019; 16: 1533.

51. Orange ST, Metcalfe JW, Liefeith A, Jordan AR. Validity of various portable devices to measure sit-tostand velocity and power in older adults. Gait Posture. 2019; 76:409-414.

52. Li FH, Sun L, Wu DS, Gao HE, Min Z. Proteomics-based identification of different training adaptations of aged skeletal muscle following long-term high-intensity interval and moderate-intensity continuous training in aged rats. Aging (Albany NY). 2019;11:4159-4182.

53. Kim HK, Hwang CL, Yoo JK, Hwang MH, Handberg EM, Petersen JW, et al. All-Extremity Exercise Training Improves Arterial Stiffness in Older Adults. Med Sci Sports Exerc. 2017; 49: 1404-1411. 
54. Fleg JL, Strait J. Age-associated changes in cardiovascular structure and function: a fertile milieu for future disease. Heart Fail Rev. 2012;17:545-554.

55. Wright AA, Cook CE, Baxter GD, Dockerty JD, Abbott JH. A comparison of 3 methodological approaches to defining major clinically important improvement of 4 performance measures in patients with hip osteoarthritis. J Orthop Sports Phys Ther.2011; 41:319-327.

56. Arnold CM, Faulkner RA. The history of falls and the association of the timed up and go test to falls and near-falls in older adults with hip osteoarthritis. BMC Geriatr. 2007;7:17.

57. Taaffe DR, Duret $C$, Wheeler $S$, Marcus R. Once-weekly resistance exercise improves muscle strength and neuromuscular performance in older adults. J Am Geriatr Soc. 1999; 47: 1208-1214.

58. Werner CM, Hecksteden A, Morsch A, Zundler J, Wegmann M, Kratzsch J, et al. Differential effects of endurance, interval, and resistance training on telomerase activity and telomere length in a randomized, controlled study. Eur Heart J. 2019; 40: 34-46.

\section{Figures}




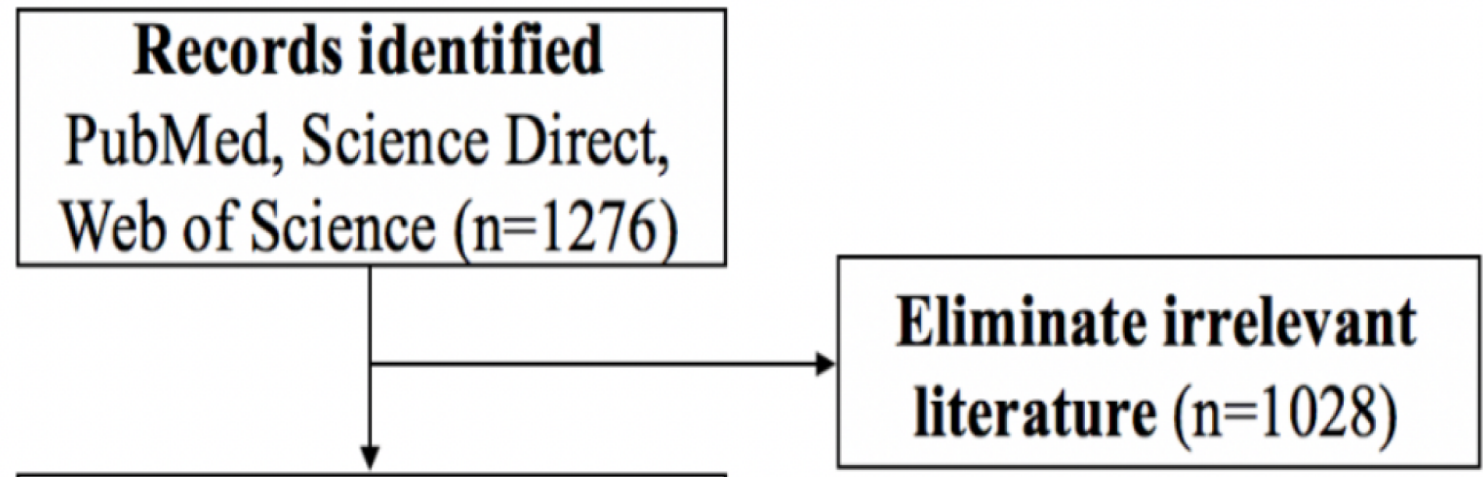

\section{Preliminary screened}

$(n=248)$

\section{Retrospective literature} $(n=23)$

\section{Probably Eligible Literature $(\mathrm{n}=271)$}

\section{Full texts included meta- analysis literature $(n=26)$}

Figure 1

RISMA flowchart of the systematic review process NPRISMA: Preferred Reporting Items for Systematic Reviews and Meta-Analyses 


\begin{tabular}{|c|c|c|c|c|c|c|c|c|c|c|c|c|c|c|c|c|c|c|c|c|c|c|c|c|c|c|}
\hline 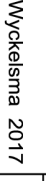 & 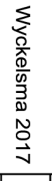 & 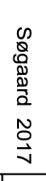 & 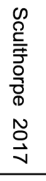 & \begin{tabular}{l}
0 \\
\multirow{2}{*}{} \\
$\overrightarrow{0}$ \\
0 \\
$\tilde{N}$ \\
0 \\
0
\end{tabular} & $\begin{array}{l}3 \\
0 \\
0 \\
N \\
\stackrel{0}{v} \\
\end{array}$ & 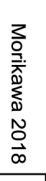 & 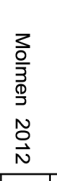 & 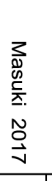 & $\begin{array}{l}5 \\
0 \\
0 \\
\mathbb{N} \\
0 \\
0 \\
\end{array}$ & 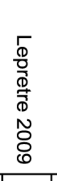 & 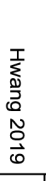 & 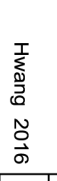 & 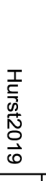 & $\begin{array}{l}Q \\
\mathbb{D} \\
0 \\
0 \\
N \\
\stackrel{0}{0} \\
\infty\end{array}$ & 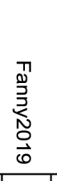 & 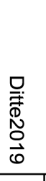 & $\begin{array}{l}\stackrel{0}{5} \\
\text { 言. } \\
\tilde{O} \\
\text { जे }\end{array}$ & 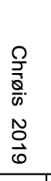 & 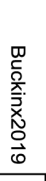 & 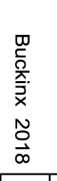 & 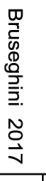 & $\begin{array}{l}\text { D } \\
\stackrel{0}{\tilde{N}} \\
\stackrel{N}{N} \\
\tilde{N} \\
\stackrel{0}{0} \\
0\end{array}$ & 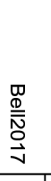 & 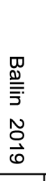 & $\begin{array}{l}\stackrel{\bar{g}}{0} \\
\vec{\Theta} \\
\Phi \\
\Phi\end{array}$ & \\
\hline$\sim$ & $\sim$ & $\sim$ & + & + & + & + & $\sim$ & + & $\sim$ & $\sim$ & + & + & + & $\sim$ & + & $\sim$ & $\sim$ & $\sim$ & $\sim$ & + & $\sim$ & + & + & + & + & Random sequence generation (selection bias) \\
\hline$\sim$ & $\sim$ & $\sim$ & $\sim$ & + & + & $\sim$ & $\sim$ & + & $\sim$ & $\sim$ & + & + & $\sim$ & $\sim$ & + & $\sim$ & $\sim$ & $\sim$ & $\sim$ & + & $\sim$ & + & $\sim$ & + & $\sim$ & Allocation concealment (selection bias) \\
\hline$\sim$ & $\sim$ & $\sim$ & $\sim$ & $\sim$ & $\sim$ & $\sim$ & $\sim$ & $\sim$ & $\sim$ & $\sim$ & $\sim$ & $\sim$ & $\sim$ & $\sim$ & + & $\sim$ & $\sim$ & $\sim$ & $\sim$ & + & $\sim$ & $\sim$ & $\sim$ & $\sim$ & $\sim$ & Blinding of outcome assessment (detection bias) \\
\hline+ & + & + & + & + & + & + & + & + & + & + & + & + & + & + & + & + & + & + & $\odot$ & + & + & + & + & + & + & Incomplete outcome data (attrition bias) \\
\hline+ & + & + & $\sim$ & + & + & $\odot$ & + & + & + & $\sim$ & $\odot$ & + & + & + & $\sim$ & $\sim$ & + & $\odot$ & $\sim$ & $\sim$ & + & $\sim$ & $\sim$ & $\odot$ & + & Selective reporting (reporting bias) \\
\hline$\sim$ & $\sim$ & $\sim$ & + & $\sim$ & $\sim$ & $\bullet$ & + & + & $\sim$ & + & $\odot$ & + & $\sim$ & $\sim$ & $\odot$ & $\odot$ & $\odot$ & $\sim$ & $\odot$ & $\odot$ & $\sim$ & + & $\sim$ & $\odot$ & $\sim$ & Other bias \\
\hline
\end{tabular}

B

Random sequence generation (selection bias)

Allocation concealment (selection bias)

Blinding of participants and personnel (performance bias)

Blinding of outcome assessment (detection bias) Incomplete outcome data (attrition bias)

Selective reporting (reporting bias)

Other bias
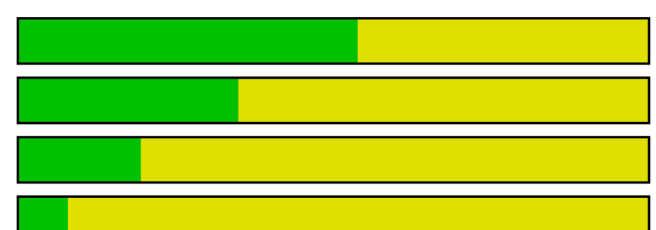

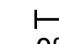

Low risk of bias

Unclear risk of bias

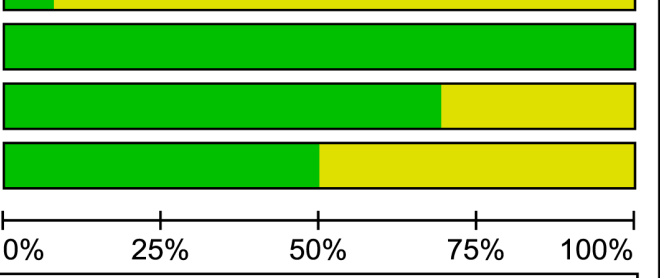

High risk of bias

Figure 2

Risk of bias assessment for the included study 
Study

ID
$\%$

WMD $(95 \% \mathrm{Cl}) \quad$ Weight
Ditte (2019)

Buckinx (2019)

Buckinx (2018)

Sogaard (2017)

Sogaard (2017)

Wyckelsma (2017)

Wyckelsma (2017)

Sculthorpe (2017)

Bruseghini (2015)

Hwang (2016)

Molmen (2012)

Ahmaidi (1998)

Lepretre (2009)

Lepretre (2009)

Kim (2017)

Chrois (2019)

Chrois (2019)

Hwang (2019)

Currie (2015)

Currie (2015)

Hurst (2019)

Overall $(\mathrm{I}$-squared $=75.4 \%, p=0.000$ )

NOTE: Weights are from random effects analysis

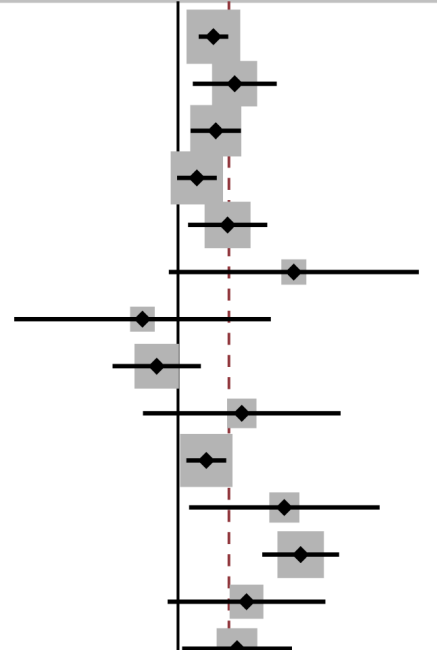

$1.50(0.88,2.12) \quad 8.05$

$2.40(0.63,4.17) \quad 5.48$

$1.60(0.54,2.66) \quad 7.15$

$0.80(-0.04,1.64) \quad 7.64$

$2.10(0.43,3.77) \quad 5.71$

$4.90(-0.38,10.18) \quad 1.42$

$-1.50(-6.92,3.92) \quad 1.36$

$-0.90(-2.77,0.97) \quad 5.28$

$2.70(-1.48,6.88) \quad 2.06$

$1.20(0.36,2.04) \quad 7.64$

$4.50(0.48,8.52) \quad 2.18$

$5.19(3.57,6.81) \quad 5.82$

$2.90(-0.43,6.23) \quad 2.85$

$2.50(0.18,4.82) \quad 4.35$

$0.60(-0.46,1.66) \quad 7.16$

$1.00(0.16,1.84) \quad 7.64$

$3.00(1.33,4.67) \quad 5.71$

$3.70(2.91,4.49) \quad 7.73$

$5.30(1.28,9.32) \quad 2.18$

$6.10(1.63,10.57) \quad 1.86$

$8.70(0.87,16.53) \quad 0.71$

$2.16(1.47,2.84) \quad 100.00$

$\begin{array}{rrr}1 & 1 \\ -16.5 & 0 & 16.5\end{array}$

B

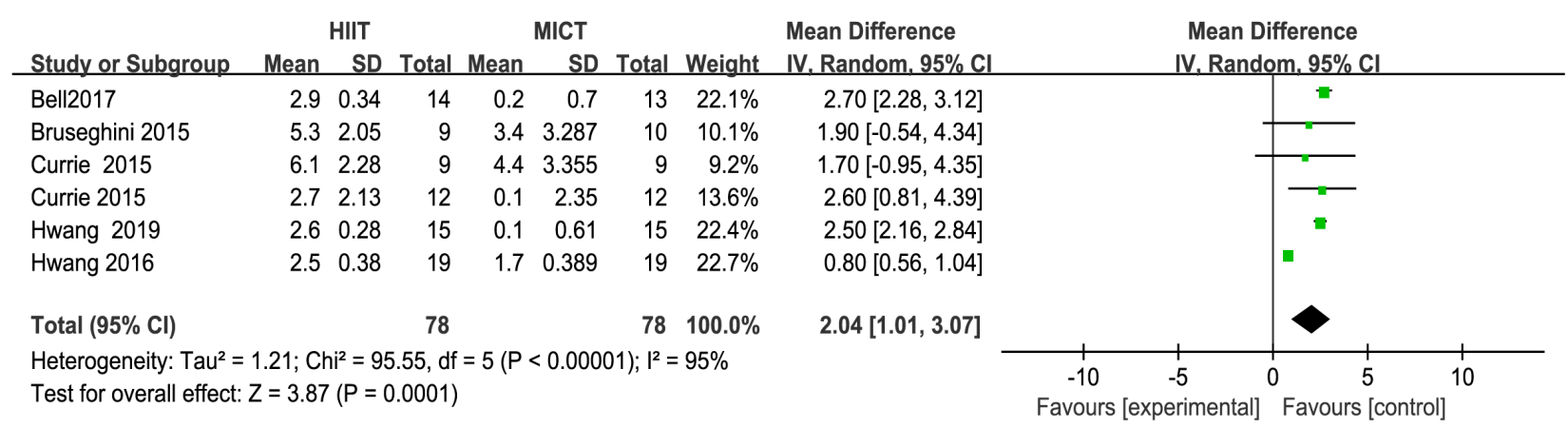

\section{Figure 3}

Forest plot illustrating: (above: A) changes in VO2max following HIIT, and (below: B) comparing the positive effects of HIIT and MICT on VO2max where the comparison made within each study analyzed HIIT vs. MICT protocols. Data shown are mean $\pm 95 \%$ confidence intervals $(\mathrm{Cl})$; the size of the plotted squares reflects the statistical weight of each study. WMD: weighted mean difference, HIIT: high-intensity interval training, MICT: moderate-intensity continuous training. 


\section{Supplementary Files}

This is a list of supplementary files associated with this preprint. Click to download.

- PRISMA2009checklist.doc 